\title{
Material Construction of Care Workers' Identity
}

I Sanna Laulainen'

PhD, Senior Lecturer, Department of Health and Social Management, University of Eastern Finland, Finland

\section{Anneli Hujala}

PhD, Senior Researcher, Department of Health and Social Management, University of Eastern Finland, Finland

\begin{abstract}
This article takes a critical look at the unconscious and unnoticed effects of materiality on care workers' identity. The data was collected through nonactive role-playing using written accounts, in which the respondents described how they felt about working in fictitious 'good' or 'bad' elderly care homes. The data was analyzed with rhetorical analysis.

Five different identity strategies were identified in the accounts. Strong professional identity was defended by downplaying the significance of materiality. Adjustment and passive compliance were used to adjust to physical shortcomings of the work environment. A 'rebellion' was described as an extreme course of action to resolve the contradiction between good care and poor facilities. At its best, the materiality of care homes, in particular homelikeness, seemed to support professional identity.

These identity strategies illustrate how care workers balance between the physical realities of care homes and the requirements of the ethos of care, which are often incompatible with each other. It is crucial that managers as well as workers themselves recognize and acknowledge these connections affecting motivation and commitment to care work. Investments in better environments could be one way to improve the image and the attractiveness of the care branch and relieve the recruitment problems.
\end{abstract}

\section{KEY WORDS}

Care worker / elderly care / identity / materiality / physical work environment / rhetorical analysis DOI

10.19154/njwls.v6il.4883

\section{Introduction}

$\mathrm{n}$ organization and management studies, the materiality of an organization has been taken (more or less) for granted. Recently the physical space where working and managing take place, the bodies of organizational actors, and the artifacts they use have been paid more attention (e.g., Ainsworth et al. 2009; O’Toole and Were 2008). This materiality has also been addressed in elderly care (see, e.g., Bechky 2008; Dale 2005; Hujala et al. 2013). In order to obtain a rich and diverse picture of the material and

\footnotetext{
${ }^{1}$ E-mail: sanna.laulainen@uef.fi
} 
physical world of elderly care organizations, we look at materiality through the lenses of organizational aesthetics (Strati 1992; Strati and Guillet de Montoux 2002; Taylor and Hansen 2005; see also Hujala and Rissanen 2011). According to organizational aesthetics the people in an organization are physical beings connected to their environment through all their senses: sight, hearing, smell, taste, and touch. Thus in this study materiality means everything we can sense in the work organization: physical spaces, concrete artifacts, and other workplace objects (and even smells and soundscape) and the bodies of other people who are present.

The context of this study is elderly care homes, which are often considered to be full of sensual experiences because they are not only workplaces but also the homes of elderly people (Martin 2002). In addition, elderly care organizations are an interesting object for the study of materiality, because both their workers and customers (residents) are closely tied to the physical settings, mostly due to the poor health of the frail residents. According to earlier studies, the physical resources of many care organizations are insufficient, including the architectural solutions and the functionality of the (work) equipment (Hujala and Rissanen 2011). This affects the well-being of both residents and care workers.

Work in elderly care is often called 'dirty work', which indicates in this particular context seeing, smelling, and touching the dirty bodily products of the elderly (see Twigg 2000; Widding 2002). This kind of dirty work is connected to the physical environment of the workplace as well. As dirty work and also as women-dominated caring work and emotionally encumbered work, elderly care carries a certain kind of 'stigma' of low status work and the low status of the nursing profession (see also Hvid and Kamp 2012; cf. Kirpal 2004). This lack of appreciation influences the identities of care workers by questioning their professional value. How the label of dirty work influences the identity of care worker in a stigmatized field is worth examining (see Slay and Smith 2011). This stigma may spread from the work identity to the area of personal life. The identity issues concern not only individual workers, but also the image and attractiveness of the whole care branch (see also Leinonen 2009). Professionals want to work in organizations where their skills are appreciated in all respects. Managerial requirements based on the ideology of New Public Management (NPM) have also undermined the ethos of public service in the last few decades and challenged the identities and identity work of elderly care workers (see, e.g., Kamp 2012; Kirpal 2004) and recognition of the emotional and bodily sides of care work (Twigg 2000). These are the reasons why the attractiveness of work in elderly care has decreased, making it crucial to study how care workers construct their identities as professionals in these circumstances.

In this article we consider how the materiality of the workplace is connected to the identity of care workers in elderly care homes. Identity has become a popular topic and frame to study various phenomena in different disciplines, for example, organization studies (e.g., Alvesson et al. 2008). One reason for the popularity of studying identity may be the purpose of managerial control of workers to enhance the productivity of the organization (see, e.g., Kärreman and Alvesson 2004). Although there are various studies on identity issues among elderly care workers and care workers more generally, studies focusing on the material dimensions of identity are quite rare (see, e.g., Bechky 2008). This article endeavors to fill this gap. The aim of this article is to illustrate and interpret how care workers construct their identity in relation to workplace materiality.

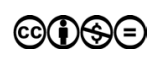




\section{Materiality and identity}

We base our approach to the material dimensions of identity from the perspective of social constructionism (Gergen 1999; Gergen and Thatchenkery 2004), extending, however, the construction to include-in addition to language and talk-the symbols and meanings embedded in materiality and embodiment (Burrell and Dale 2003; Dale 2005; see also Ainsworth et al. 2009; Michael 1996). The physical spaces and concrete workplace objects, for instance, are social constructions as such, not just neutral walls of buildings or objective artifacts. In addition to this, materiality also constructs human beings: people make spaces, but the spaces 'make' them, too (Burrell and Dale 2003). Just as we leave our footprint in the physical environment we live in, the environment also modifies us by constructing and reconstructing our identities.

From the point of view of identity, this means that our identity is both socially and materially constructed, and this construction goes on continuously. When we ask, 'Who am I?' or 'What is it to be a care worker?' the answer is not (solely) in our own hands. Gergen (1999, p. 43-44) states that 'we are made of each other'. Our identity is also our social reputation; it is dependent on how we are represented in others' talk and minds. In a similar way, our identity is connected to the material environments where we work and live and to the meanings we and other people attach to that materiality.

Studies on the connections between materiality and identity have been summarized by Bechky (2008; see also Elsbach 2003, 2004). Schraube and Sørensen (2013) have addressed materiality in their discussion on subjectivity. Bechky (2008) highlights that artifacts (like décor and clothing) influence the development (e.g., maintaining and legitimizing) of identities in organizations and therefore it is interesting to study how people use the objects in their working practices. One example of the impact of materiality is Elsbach's (2003) research on nonterritorial work environment and how it threatened workplace identities and, for example, the stability of status hierarchies. These results applied to the context of elderly care homes serve to render comprehensible some potential impacts of homelikeness which is a mainstream development in the field.

In addition, identity has been studied especially in relation to scents (smells, odors; see Corbett 2006), spaces (see Ainsworth et al. 2009; Fine 1996; Halford and Leonard 2006; see also Jacobs and Malpas 2013), and the body (see Harquail and King 2010). All these highlight the material basis of the formation of human life. For example, the scents are often an unnoticed part of organizational life with unconscious impacts (see Corbett 2006) and may influence identity construction in dirty work. As Twigg (2000) points out, care work as bodywork is at the same time obvious but hidden or silenced. Dealing with human waste and touching frail bodies compel care workers to adopt coping strategies. These strategies help to understand how the material aspects have an impact on care workers' identities.

Materiality in the form of space should not be seen as 'material' stuff but as a structure of self-formation, of self-articulation, and of self-remembrance (Jacobs and Malpas 2013). It highlights the evident nature of spatial and temporal basis in the construction of workplace subjectivity (see Halford and Leonard 2006) and identity (Ainsworth et al. 2009). In a study on the National Health Service (NHS) (Halford 
and Leonard 2006) the opportunity for workers to make active use of specific spatial and temporal resources for constructing and performing subjectivities was present but at the same time power relations intertwined in the contextual aspects restrict it. This encourages us to consider how materiality can be used actively as a resource in identity re/construction or how it may impede it. It also enables us to scrutinize what kind of strategies people use in response to material restrictions which may threaten identity (see also Elsbach 2003).

The most common approach in the field of identities and its link to materiality has been to consider the material as a means of self-presentation, for instance, as a signal of nurses' professional identities (Elsbach 2004) and addressing the significance of the uniforms used (Pratt and Rafaeli 1997). Elsbach (2004) emphasizes how office décor (e.g., furniture, photos) impacts on interpretations concerning workplace identities. It helps to comprehend, for example, how different social categorizations regarding status are linked with material surroundings. Pratt and Rafaeli (1997) point to how dress is used in various ways in organizational settings as a symbol of identity. Their study revealed how clothing carries meanings of appropriateness obeying the professional demands and identity. Harding (2002), too, points out how the managerial body is constructed (subjectified/objectified) as a product like dressing someone as a manager and rendering bodies into internalized forms of control.

In her research on clothing in the maintenance of identity in the context of dementia, Twigg (2010) illustrates the significance of clothing as a form of habitual embodiment, as the immediate sensory surroundings of the person, as a state of social standing, and as regulating the body. Clothing is a way to perform identity. In addition, she studied the significance of handbags as part of the life stories of people with dementia and as a way to cope with lack of privacy in care home settings (Buse and Twigg 2014). However, in the context of dementia the significance of clothing and accessories should be considered critically with regard to people with dementia and also caregivers. As Twigg (2010) points out, the meaning of these material things varies and should not be exaggerated even though clothing, for example, offers important insight to comprehend the material basis of identity.

Critical studies on identity (see Jaros 2012; Thomas 2009) have focused on such things as how identities and subjectivities are manufactured, regulated, and controlled, as well as on themes such as dis-identification and identity resistance. Organizations and employers also manipulate workers' identity through materiality (Harding 2002; Kunda 1992), which can be interpreted as a form of managerial control (e.g., Kärreman and Alvesson 2004), even extending it to the level of everyday life (Hancock and Tyler 2004) and enhancing the 'fun' factor of work (Baldry and Hallier 2010); the latter being an example of how work space is designed to support a range of officially encouraged 'fun' activities at work. The critical perspective in the present study addresses the taken-forgranted and unnoticed effects of materiality on identity.

To sum up, most of the earlier studies addressing materiality have focused on bodies, dress, and accessories. In this article the focus is mainly on the physical environment. We are interested in how care workers position themselves as professional actors in relation to the physical work environments of elderly care homes. As Widdicombe (1998, p. 200) points out, the traditional definition of individual identity 'who I am' goes hand in hand with the spatial interpretation of identity by also asking 'where am I?' and here in particular 'where do I work?'

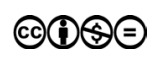




\section{Study design}

This study forms part of a more extensive research project on well-being in elderly care (Constructing wellbeing in elderly care-organization, design and management as key elements, CoWell; Hujala et al. 2013). The study was conducted in residential elderly care homes.

For the present substudy we gathered data from care workers working in elderly care homes in Finland through written accounts during the period 2010-2011. The method used in the data gathering was nonactive role-playing (e.g., Eskola 1988) through accounts written by care workers. Eskola defines nonactive role-playing as a method that interferes in the subject's emotional and cognitive world. It consists of writing short essays in which 'subjects are asked to picture themselves in a certain situation that is described to them and then imagine and write how the situation proceeds, what must have preceded it, etc.' (Eskola 1988, p. 240). One key element of the method is to vary certain elements of the reality described in the script (called the frame story) and to analyze how this variation affects the stories. Eskola (1988) used the method as a lighter alternative to the experiment and the focus of analysis can be on situation logic, the dynamics of the process or relationships, and prediction of future events.

We sent out a total of 185 requests to participate in the study to 22 elderly care homes. The managers of these care homes randomly passed on these requests to the staff. The request included the frame story and writing instructions. Half of the requests were about working in a good care home and half in a bad care home. These were described in a few sentences in the frame stories (see below). These frame stories were our (authors') own constructions based on the findings in the CoWell project. The purpose of the frame stories was to evoke and 'recreate' the aesthetic experiences of the care workers while writing their own stories (see Warren 2008). In addition, we asked for some background information: age, sex, position at work, and experience in the care branch.

\section{Story about 'The Good Care Home'}

The facilities of the Good Care Home are pleasant. The work spaces and the equipment are appropriate. The staff offices are sufficiently spacious. For meetings there is a separate, quiet room. The staff meals and other breaks are well arranged. The care home not only looks good, but also smells, tastes, and sounds attractive.

Immerse yourself in the following situation. Imagine that you are inside the Good Care Home and in the middle of its daily work as an employee. Write a story (1 to 2 pages) on this paper about what it is like to work in the nice facilities of the Good Care Home. How do the facilities described above and the other physical work environment affect your work self? And how are they linked to your own well-being as an employee?

MY STORY AS AN EMPLOYEE OF 'The Good Care Home'... 


\section{Story about 'The Bad Care Home'}

The facilities of the Bad Care Home are unpleasant. The work spaces and the equipment are not appropriate. The staff offices are too small. For meetings there is no separate, quiet room. The staff meals and other breaks are badly arranged. The care home not only looks bad, but also smells, tastes, and sounds unattractive.

Immerse yourself in the following situation. Imagine that you are inside the Bad Care Home and in the middle of its daily work as an employee. Write a story (1 to 2 pages) on this paper about what it is like to work in the poor facilities of the Bad Care Home. How do the facilities described above and the other physical work environment affect your work self? And how are they linked to your own well-being as an employee?

MY STORY AS AN EMPLOYEE OF 'The Bad Care Home'...

In the frame stories good and bad referred to the quality of the physical environment of a fictitious care home. Each worker was asked to write a story about what it would be like to work in the nice/poor facilities of the good/bad care home depending on the frame story s/he had been giving, beginning from the moment when they open the outside door of the care home and step inside. They were asked to describe, in particular, how the physical work environment affected their work self and their own well-being as an employee.

Altogether 41 short stories were returned, 21 of them using the frame story of a good care home and 20 the frame story of a bad care home. Because the details of the background organization were not elicited we do not know from which of the 22 care homes stories were returned. All except one of the respondents were female. The average age was 45 years (range 19-61 years). The most common job position was that of practical nurse. The respondents had worked in the care branch on average 14 years (range $0-27$ years). The length of the stories varied from a half page to three pages. The stories were quite short but nevertheless illustrative.

It is noteworthy that the stories varied in such a way that those stories about the bad care home were described more 'factually' and those stories about the good care home were idealized as 'dreams'. We elaborate this more in the findings. This division into 'facts' and 'dreams' may indicate respondents' own negative experiences in practice even though it is impossible to claim this on the basis of the stories. In their stories about 'good' and 'bad' care homes, the care workers described the material environments mostly in relation to their concrete care work. We recognize that the frame stories have an impact on how materiality was illustrated in the stories of care workers. The emphasis was on work spaces, equipment, staff offices, break arrangements and smells, taste, and soundscape even though their illustrations were not restricted to these.

The positive connection between materiality and identity was mentioned less often in written accounts than its negative connections. Some stories included detailed descriptions of the physical conditions and also reflected the emotions aroused by the material environment. Many stories, however, were off-topic, in a way focusing solely on the care work and 'omitting' to focus on the material dimension requested. In spite of 
the instructions given in the frame stories, only a few writers reflected explicitly on the identity issue or their own well-being. Instead, the well-being of the clients, the elderly people, was focused on. One of the stories was even written from the perspective of the elderly resident, not from the worker's point of view.

We analyzed the data (41 written short stories) with rhetorical analysis, based on Billig (1996), Jokinen (1999), Potter (1996), and Shotter (1993). The focus of our analysis was on how the care workers in their accounts constructed their relation to the materiality in the fictitious organization. More precisely, our analysis focused on how the care workers positioned themselves and other actors in relation to the material reality of the elderly care home (on justifying practices and positions through rhetorical devices; see, e.g., Grant and Hardy 2004). We also paid attention to what kind of specific 'functions' the rhetorical talk served (see Symon 2000, p. 479) and what consequences the talk seemed to give rise to. We were more interested in the argumentative and contextual nature of rhetoric than in linguistic tactics (see Symon 2000, p. 479).

The accounts of the care workers ${ }^{1}$ do not mirror reality as such, nor are they supposed to represent 'real' experiences and the analysis is not supposed to reveal the simple and ultimate truth about the effects of materiality on identity (on the idea of deconstructing 'reality' see Symon 2005). Talk is social action and care workers in their accounts take different positions in regard to their physical work environment and thus construct their identity, too. They presented and justified the particular perspective on reality to an audience, thereby arguing against other perspectives implicitly or explicitly (Symon 2000, p. 478). We do not refer to rhetoric as purely intentional manipulation or persuasion. Instead, we take the view that talk is always in a sense rhetorical: even in everyday life we-intentionally but perhaps even more often unintentionally-try to make our talk plausible (Symon 2000).

In their accounts the care workers, intentionally or unintentionally, make arguments, try to convince their audience, present claims, criticize, legitimize, downplay, and bring to the fore diverse issues (Jokinen 1999, p. 128; Potter 1996). In these rhetorical ways a new understanding of the connections between materiality and identity is constructed in this particular context.

The ethical principles of the study followed the general guidelines stipulated by the Finnish Advisory Board on Research Integrity on research ethics. The respondents maintained their anonymity because no names or affiliations were elicited in the background questions. According to the general ethical guidelines we have tried to illustrate our premises and describe the phases of the study. Evaluating the trustworthiness of a study based on the nonactive role-playing and rhetorical analysis is challenging. The number of stories was sufficient (there were hints of saturation in the stories which is one way to know when to end data gathering with this method) given the method of data gathering and analysis. The dichotomy of the study design (frame stories about good and bad care homes according to nonactive role-playing) can be called into question. This categorization itself is already one rhetorical way to present reality.

In the following we first describe the materiality of care homes and then present our findings as identity strategies through the rhetorical ways which the care workers used while describing their relation to the workplace materiality. In these interpretations our purpose is to highlight how materiality matters and is intertwined in identity. 


\section{Findings}

\section{Materiality of the care homes}

\section{Good care homes}

Good care homes were described as 'dreams'. In these strikingly 'ideal' descriptions care workers often used the conditional tense like 'In this kind [illustration of the good care home] of environment I would feel good. This is what I dream of' (G4). One care worker named the perfect care home as 'The Happy Place' that produces 'the joy, light and spark of work' (G10). These descriptions reiterate the wishes concerning their work expressed by care workers in earlier studies (e.g., Leinonen 2009).

Very often good materiality was connected in the accounts with cozy, peaceful atmosphere and homelikeness, including the opportunity for residents to take part in daily activities like baking and gardening. The ideal of homelikeness is one of the most dominant discourses attached to the physical environments of care homes. It calls to mind the ongoing political debate in Finland on supporting elderly people to continue living at home for as long as possible. A good care home looks and feels like a home. In the accounts it is typical that care workers illustrated good materiality through, for example, the aroma of freshly baked buns and coffee, the sound of silence or calming music, ergonomic and stimulating furniture and space, relaxing colors, and delightful flowers. Through these material issues the care workers highlight the opposite of clinical surroundings. There is room enough and proper and inspiring facilities for living with dignity. The ambience is peaceful and care workers have time to socialize and physically encounter residents in addition to official care. These features of good care echo the desired future of elderly care (Leinonen 2009).

In many cases the care workers' accounts confirmed the discourse in which the homelikeness of the care home environment is taken as an expression of both good care and professionalism. One's own work and work environment were explicitly equated with 'home'. This is illustrated in the extract below by using a metaphor of family and highlighting a transition from working to spending time and looking after.

In actual fact I don't feel I'm 'working', but spending time in a big family where everybody looks after each other and takes the others into account. (G32)

\section{Bad care homes}

From the rhetorical point of view, the way care workers described the environments of 'bad care homes' can be viewed as factual construction (Jokinen 1999; Potter 1996). It is an extreme way of producing convincing rhetoric: it aims to report an absolute truth about how things actually are. The descriptions are made to look as if they were not dependent on the speaker and her/his interpretations. For example, the following descriptions of the physical premises of care homes were produced 'simply as facts' and raise questions about the ethicality and quality of care. 
The rooms are cramped and impractical. The lighting is wrongly aligned. The shower room is impractical. The windows are high so that from a wheelchair there is no proper view to the outside. (B5)

These 'authentic' descriptions of bad care homes were reported very neutrally and objectively, as if the care workers were reporting something that is commonly known and confirmed and over which the workers themselves can exert no influence.

The stories about bad care homes included very rich and detailed descriptions and revealed in an illustrating way the multi-sensory nature of physical care environments. The most common deficiencies were poor condition of equipment, inadequate size of rooms, especially toilets, narrow and dismal corridors, poor ventilation systems, cold shower rooms, restless soundscape, and smells of drains, mold, and urine. The label of dirty work was subsumed in accounts as in the next extract. Reference to the familiarity of smells emphasizes smell as a fact and form of dirty work in mundane practices.

I open the door to the communal facilities. The familiar smell of body fluids, food, stuffy mold and drying laundry reaches my nose. (B6)

The shortcomings which were most closely related to the workers themselves (and not particularly to the residents, which were more commonly mentioned in the accounts) were staff changing rooms (cramped, stuffy, and awkwardly situated in the basement of the building), lack of room for having lunch or coffee or other breaks. Moreover, offices, if there were any, were too small and there was a lack of meeting rooms.

\section{Identity strategies in relation to workplace materiality}

\section{Downplaying materiality}

The most distinctive feature in the care workers' accounts was the downplaying of the significance of materiality and underlining care workers' role and the ethos of care. The strong professional care workers' identity is thus constructed regardless of material surroundings and even as an opposite to materiality. At least for us researchers, this was something of a surprise, because our earlier findings from interviews and observations, partly in the very same organizations, had revealed considerable shortcomings related to both the spaces and (work) equipment (Hujala and Rissanen 2011).

The following two extracts show how the relevance of materiality is downplayed, and even occasionally denied and how the strong professional care workers' identity is constructed through it. In the first extract a care worker underlines the importance of facilities only as the framework for work and uses capital letters to highlight the role of care personnel instead. In the second extract care worker excludes the significance of materiality as a premise for care work.

As I go on shift I feel the joy, light and the fire of working. (...) Great facilities only provide the framework, it's the care personnel that creates the ATMOSPHERE. ${ }^{2}$ (G10) 
No external things can create a sense of meaning, even though they are very important if the work community does not function properly and the climate is oppressive. (G22)

The ethos talk can be interpreted from the perspective of the relationship with the audience, which is salient in rhetoric. Rhetorical talk is always addressed to an audience, real or imagined. Downplaying materiality can be interpreted as convincing the audience of one's professional worth (see Symon 2000, p. 482). The audience in this case may comprise managers, old people, or their relatives. The audience may also be the speaker herself/himself, and this kind of talk becomes an 'internal dialogue' in which a care worker convinces herself/himself of the importance of her/his own work. Downplaying the relevance of the physical work environment thus serves to defend a worker's own professionalism. It can be interpreted as a way to cope in inconvenient working conditions and reassert one's own professional identity.

It is noteworthy that downplaying materiality occurred more often in the stories of good care homes than stories of bad care homes. From a critical viewpoint, downplaying can be interpreted as a need to emphasize the ethos of good care and the role of the care worker in producing it. Material resources merely provide the setting in which the action takes place.

\section{Adjustment to poor materiality}

Adjustment to poor materiality highlights the care worker's identity as an adaptable survivor who tolerates restrictions. The care worker makes active use of all her/his capacities to complete tasks as good care professional despite physical circumstances.

In the written accounts poor physical care environments are described as a fact which one has to accept; there is no other option or way to intervene. Care workers 'normalized' these dysfunctional surroundings and reacted by adjusting. The virtues of kindness and modesty emerged. The compulsory adjustment as an inbuilt ethos of surveillance is illustrated in the extract below. This particular example highlights various aspects of materiality as part of care work. In addition, it shows how professionalism in the context of care work in materially encumbered circumstances includes numerous skills and the compulsion to adjust.

The smell is pretty bad by the time I reach my first client. (...) I curse under my breath that not even the air conditioning is working but I take my client to the little WC where it is difficult to fit in with a wheelchair. I use all my acrobatic skills and get my client onto the WC pedestal and get her washed. I straighten my back, which is hurting already although I'm only on my first client. (...) I wipe sweat from my forehead, try to stay calm in front of the clients and if I could just get something like a smile onto my face. (...) I go about like a robot until the end of my shift, give my report to the night shift workers and go to the changing room to change my clothes. (B34)

Care workers may use different survival strategies by utilizing all their, almost incredible abilities (as acrobats) and routines (work like a robot) and doing emotional work (like trying to calm down and smile and curse silently; see Hochschild 1983, cf. Ward and McMurray 2016) to accomplish the professional demands of care work. These strategies 
emphasize both active personal investments and nonpersonal manners. This particular example also underlines how these survival strategies are intertwined in bodywork on the part of care workers and residents (see Twigg 2000).

In addition, in the next extract the care worker uses the term magician and confirms its meaning with the term 'coping in the madhouse' to refer her special abilities to survive.

I have made quite a few requests for repairs but nothing happens. Will it happen if there's an accident and a patient breaks her hip falling out of a broken chair. (...) I'm quite a magician when I cope in this madhouse... there has been talk of the future, a repairs and improvements promised, but nothing has happened-maybe some time in the future. I drag myself home, tired. I think that things will go better tomorrow. (B37)

In this extract, as in several other accounts, adjusting to conditions (because nothing happens in spite of requests) is apparent. No-one is responsible, nothing can be done. This was also produced by such rhetorical ways as negative repetition or making the situation a continuous-and hence naturalized-phenomenon. One way to underline the 'normalized' nature of the problem is continual references to complaining and appealing without impacts as the extracts below illustrate. The second extract shows how this care worker has no option but to tolerate the situation. It constructs quite a passive role for the care worker in relation to developing the material surroundings.

A resident is complaining about the noise of traffic which is too often heard indoors. She says she couldn't sleep properly for the noise. I tell her I am sorry and decide to take the matter up at the next weekly meeting. We have been complaining about poor sound insulation for years but nothing has been done about it. (B38)

... I have mentioned this [material problem] at least a hundred times, but no costs may be incurred. I am not the one who is supposed to be complaining. (B16)

Adjustment as an identity strategy confirms lack of active agency. Adjustment is inevitable to survive in the field by utilizing all professional and other capacities to manage in poor facilities.

\section{Passive compliance to material shortcomings}

At its worst adjustment leads to passive compliance. The 'bad' stories especially include many descriptions, in which workers seem to compliantly accept the material shortcomings as if they were unchangeable and taken-for-granted restrictions for work. Passive compliance differs from adjustment so that workers do not even try to exert influence. They just acquiesce to the situation. It may confirm the identity of indifference. In the next extract passive compliance is constructed as a consequence of dysfunctional spaces. In addition, the care worker confirms her indifference by stating that her salary is her reason for working. The reason for passive compliance as an identity strategy may be the fear of the consequences of reacting as shown in the next extract. 
The facilities and their lack of functionality are conducive to passivity. We work because we are paid for it. Enjoyment is not a motive for many. (B17)

If somebody tries to address deficiencies she is silenced and possibly even sacked. (B1)

This strategy of passive compliance produces indifference and is clearly connected with exhaustion and work motivation problems. It may also lead to an identity of 'victim'. There is one particular extreme example of passive compliance and how it confirms the identity of 'victim'. This is shown in the next extract in which bodily aspects of care work are underlined. By questioning what the care worker had done wrong when she had to tolerate physical and mental violence as a 'normalized' part of caring for residents with dementia she emphasizes how professional identity is intertwined strongly and in various ways in bodily encounters. She may find herself in a position of victim which is inconsistent with the expectancy of professional care work. However, it is interesting how in this particular example the care worker balanced between understanding the behavior of her resident and questioning silently why she had to endure.

S/he [a relative] doesn't seem to understand that dementia has changed her/his mother's personality. She is no longer the same gentle mother smelling of baking but a querulous, scratching, spitting old woman who is difficult to care for. (...) In my mind I wondered what I had done wrong when in my work I have been hit, scratched, spat on and called a whore, an old cow and so on. I understand that a demented resident does that out of spite, but scratching, hitting etc. hurts just the same as if it had been done by a drunk, for example. (B20)

Even though the identity of 'victim' is a strong interpretation of passive compliance it highlights how materiality may restrict good professional care work and broaden the bodily aspect of care work by bringing up shortage of integrity as professional entitlement.

\section{Relying on materiality}

In both the good and bad care home accounts there were arguments that highlighted the significance of materiality as a basis for implementing the ethos of care work and entitlement to facilitating surroundings. Through these arguments care workers use materiality to support their professionality. In this kind of rhetoric both the content and the form of the talk produce social categorization of care workers due to the quality of the physical work environment. The descriptions refer to the appreciation-or the lack of it—which is embedded in the materiality. In a positive manner, the workers addressed the appreciation issue as follows:

It's nice to come back to work, as crazy as that sounds... Good facilities motivate and encourage you to work. They give a sense that we are really appreciated, both as workers and as people. We are important. We matter! (G12)

As a visual person the environment of the Good Care Home for me is like my own home. (...) In such an environment I would really feel well, this is what I dream of. (...) A pleasant 
environment means a great deal to me, it gives me more energy and if I can be involved in implementing it. Such an environment also means that the worker is appreciated. (G4)

In the first extract above the care worker underlined what a strong impact materiality has on identity. The care worker uses repetition and an exclamation mark to confirm the impact that materiality has on how care workers feel about themselves. In addition, materiality impacts on the motivation and encouragement of the care worker which are both intertwined in identity. The second extract underlines these issues as well.

One way to emphasize entitlement to good material facilities is glorifying homelikeness as a wish and display of appreciation as in the next extract.

As a visual person the environment of the Good Care Home for me is like my own home. (...) In such an environment I would really feel well, this is what I dream of. (...) A pleasant environment means a great deal to me, it gives me more energy and if I can be involved in implementing it. Such an environment also means that the worker is appreciated. (G4)

We can interpret the aspiration to homelikeness as a basis for well-being and promoter of productivity and good quality but also conversely as a way to reduce the gap between professionals and residents. In the extract below reconstructing the identity of a professional as a family member is illustrated almost like a dream even though in the last sentence the more traditional professional role arises.

In the premises of the Good Care Home one doesn't feel as if one were 'at work' but rather having gone to visit old aged friends whom I help with their everyday and special day chores while I talk to them and when evening comes I wish them goodnight. In good surroundings it comes naturally to cheer people up. As a worker in these surroundings I can give the best possible account of myself for the benefit of the residents, my employer and my colleagues. (G8)

In the extract above the homelikeness as a material surrounding and space for encountering is naturalized as a starting point for good care work in which professional identity gets more nonprofessional features. At its best, materiality of care homes, in particular homelikeness, seemed to support professional identity.

\section{Rebellion against material shortcomings}

Above we described how care workers constructed their own identities as survivors who can only acquiesce to the material conditions around them and as dedicated good professionals to whom the materiality of the workplace does not matter or does, indeed, matter by constructing the basis for conducting the ethos of care. It is interesting that even though there were numerous examples in the accounts of material shortcomings and the problems caused to care workers and their identity there were only few accounts consisting of identity of 'rebel' and the counterpositions that care workers actively choose as identity strategies.

The next extract illustrates so-called micro-level rebellion, working contrary to official instructions. This example brings to the fore how the identity of 'rebel' is constructed 
occasionally when the circumstances cry out for counteractions and counterpositions. An urge for humanity legitimizes a care worker's action which can be labeled minimum compared to material shortages that are illustrated more widely in the accounts of 'bad care home'. In the extract the care worker is convincing in showing that the counteract is compulsory by putting into juxtaposition the suffering of residents and carers and the technical orders.

The men from the technical facilities department forbade ventilation through the window so that the air-conditioning would not suffer, but at times it must be done so that the residents and carers don't suffer. (B20)

There was only one example in the accounts of rebellion against material shortcomings. In the example (extract below) rebellion was constructed as a result of the insanity that the care worker felt. She legitimized her decision to resign by illustrating the bad behavior of the manager and how it reveals problems in the material surroundings. The care worker used exclamation marks and capital letters and strong expressions as rhetorical devices to convince that she was in a way forced to opt for this ultimate solution because it was against the professional identity of her education.

The manager comes out of her office, looking angry. 'Hey you!' she cries, annoyed. Was it you who complained to the occupational health authority about the changing room? Did you also mention that the beds are not as they should be? We're going to be inspected by both the occupational safety and the patient ombudsman. Do you realise how much that circus and all the alterations are going to cost??!'

Something goes snap in my head. I glance around me. (...) I can see everything clearly, the drawbacks, deficiencies, the dissatisfaction that can be sensed in both staff and residents... This can't go on. This isn't why I studied all those years... NO. ${ }^{4}$

I turn to the manager and say: Now, at this very moment, I RESIGN. ${ }^{5}(\ldots)$ I will never come back here again! I turn round and walk to the changing room where the walls are decorated with mould, and change into 'civvies'. I'm disappointed in myself, I tried to go on, but I didn't have the energy. I'm truly exhausted! (B6)

It is noteworthy that even in this particular example of rebellion in which a care worker tried to intervene in material shortcomings and resigned suddenly the care worker expressed disappointment with her own coping and her decision to resign even though the circumstances seem to be senseless and unfair. The extract illustrates that it is a virtue in a care worker to adjust and survive in spite of anything that comes along. It shows how a care worker balances between responsive, acquiescent, and rebellious identities. It furthermore deconstructs some of the basic assumptions that are intertwined in the identities and ethos of care workers as self-evident virtues.

The reason for resigning as a form of rebellion was professional, even though there was quite a strong emotional charge in the extract. Appealing to the lack of opportunities to fulfill professional requirements is one way to underline her entitlement to construct and present her as competent professional care worker. 


\section{Discussion and conclusions}

This article focused on care workers' identities in relation to workplace materiality. By materiality we meant physical work environments, which refers to all we can sense there: physical spaces, concrete artifacts, and other workplace characteristics (including, e.g., smells and soundscape) and the bodies of others present. The material aspects of workplaces are often ignored in identity research and critical perspectives to 'reveal' the effects of these taken-for-granted material dimensions on identities are needed. The purpose of this study was to respond to this need by highlighting the importance of physical environments in the context of care work.

We approached the relation between identity and materiality through the use of rhetoric in imaginary stories written by care workers. In their accounts the care workers constructed good care homes as 'dreams' and bad care homes as 'facts'. These categorizations were constructed by elaborating various aspects of materiality like spaces, facilities, objects, smells, and bodies. It is noteworthy that the 'black and white' construction of bad and good care homes was partly due to the dichotomy of the frame stories which already as such was a rhetorical way to represent reality. These results cannot be generalized as a description of the reality of elderly care homes more widely even though they help to comprehend how materiality is intertwined with identity construction in this particular context.

Five identity strategies were identified in the accounts. Like Elsbach (2003), we found identity strategies that people use in response to material restrictions which may threaten identity, but in addition we found strategies in which identity was based on material surroundings in a more positive way. Strong professional identity was defended by downplaying the significance of materiality. Adjustment and passive compliance were ways to overcome the physical shortcomings of the work environment. A 'rebellion' was described as an extreme way out of the contradiction between good care and poor facilities. At its best, the materiality of care homes, in particular homelikeness, seemed to support professional identity. These identity strategies illustrate how care workers balance between the physical realities of care homes and the requirements of the ethos of care, which are often contradictory.

Firstly, the ethos of care highlights the view that materiality is merely a framework for care work. Dedicated care workers manage to do their best in spite of the material surroundings. This was illustrated by downplaying the materiality. However, this finding raises a question as to how far we can count on the ethos of care if no improvement in the material basis is achieved. This is an important issue due to the strong emphasis of the ethos of care in identity strategies. There was only one exception to this in the form of rebellion. This exception underlines the significance of the ethos of care as a basis for professional identity.

Secondly, another option, adjustment or compliance-when there are considerable shortcomings in the physical environment-is an understandable but also alarming identity strategy in the accounts. Adjustment confirmed that coping and 'surviving' no matter what is one professional requirement of care work. Twigg (2000) likewise points out that coping strategies are important in care work when doing bodywork and 'dirty work'. We argue that in our research the 'I cannot influence this, so I don't care' approach may be connected to a more widespread lack of motivation for and commitment to care work. It resembles the problems related to dirty work and can be a threat 
to strong professional identity and even lead to cynicism and burnout. It is worth asking how management could involve care workers more in developing care environments to meet the needs of both residents and workers (Hujala and Rissanen 2011). This involvement could be an efficient way to support the motivation and commitment of care workers and to achieve more productivity and better quality. It could also be a sign of appreciation which may strengthen professional worth and identity in a field that is stigmatized (see also Hvid and Kamp 2012).

Thirdly, the findings also suggest that good physical facilities are connected with appreciation and they constructed a basis for strong professional identity. Material surroundings thus mediate the values of the organization. It can be seen as a way of showing appreciation. Therefore materiality impacts in a significant way on the identity re/construction of care workers and how they see themselves as professionals in the context of 'dirty work'. However, using material objects as a manifestation of professional pride is quite untypical for care workers in contrast to professions such as managers or doctors, who seem to use materiality as a tool to emphasize identity and status (Bechky 2008). One example in which materiality could threaten professional status and identity is a nonterritorial work environment (Elsbach 2003). Homelikeness could be labeled as such an environment. However, in the written accounts homelikeness was present as a metaphor for good surroundings in which to accomplish professional care work. The care workers did not criticize homelikeness except to illustrate how staff's private space may be lacking. This lack of organizational space (see also Martin 2002) and assuming that the workers are like family members constantly available to residents can be interpreted from the critical approach as a manufacturing of appropriate individuals for care work (see Alvesson and Willmott 2002; Harding 2002; Thomas 2009).

The quality of care work has been under scrutiny in research and in public discourse in Finland and more widely due, for example, to the major big challenges of ageing population and limited amount of resources to provide services for them. It is crucial that decision-makers, managers, and the workers themselves in the field of elderly care recognize and are aware of the significance of materiality in various ways and the connections between materiality and identity issues. In a broader sense, the appreciation-or lack of it-embedded in materiality may be one of the key factors in efforts to enhance the attractiveness of the care branch and ensure the availability of labor in the future. Hence further insights on the material construction of identity in the care branch and in other professional contexts are more than welcome.

\section{References}

Ainsworth, S., Grant, D. and Iedema, R. (2009) “"Keeping Things Moving”: Space and the Construction of Middle Management Identity in a Post-NPM Organization', Discourse \& Communication 3(1): 5-25. doi: http://dx.doi.org/10.1177/1750481308098762

Alvesson, M., Ashcraft, K. L. and Thomas, R. (2008) 'Identity Matters: Reflections on the Construction of Identity Scholarship in Organization Studies', Organization 15(1): 5-28. doi: http://dx.doi.org/10.1177/1350508407084426.

Alvesson, M. and Willmott, H. (2002) 'Identity Regulation as Organizational Control: Producing the Appropriate Individual', Journal of Management Studies 39(5): 619-644. 
Baldry, C. and Hallier, J. (2010) 'Welcome to the House of Fun: Work Space and Social Identity', Economic and Industrial Democracy 30(1): 150-172. doi: http://dx.doi. org/10.1177/0143831X09351215.

Bechky, B. (2008) Analyzing Artifacts: Material Methods for Understanding Identity, Status, and Knowledge in Organizational life. In D. Barry and H. Hansen (eds.) The Sage Handbook of New Approaches in Management. London: Sage, 98-109.

Billig, M. (1996) Arguing and Thinking. A Rhetorical Approach to Social Psychology. Cambridge: Cambridge University Press.

Burrell, G. and Dale, K. (2003) 'Building Better Worlds? Architecture and Critical Management Studies'. In M. Alvesson (ed.) Studying Management Critically. London: Sage, 178196. [Electronic book] Available: doi: http://site.ebrary.com/lib/uef/docDetail.action?docID=10076711. Accessed 26.3.2014.

Buse, C. and Twigg, J. (2014) 'Women with Dementia and Their Handbags: Negotiating Identity, Privacy and 'Home' through Material Culture', Journal of Aging Studies 30: 14-22. doi: http://dx.doi.org/10.1016/j.jaging.2014.03.002.

Corbett, M. (2006) 'Scents of Identity: Organization Studies and the Cultural Conundrum of the Nose', Culture and Organization 12(3): 221-232. doi: http://dx.doi. org/10.1080/14759550600871469.

Elsbach, K. D. (2003) 'Relating Physical Environment to Self-Categorizations: Identity Threat and Affirmation in a Non-Territorial Office Space', Administrative Science Quarterly 48: 622-654. doi: http://dx.doi.org/10.2307/3556639.

Elsbach, K. D. (2004) 'Interpreting Workplace Identities: The Role of Office Décor', Journal of Organizational Behavior 25(1): 98-128. doi: http://dx.doi.org/10.1002/job.233.

Eskola, A. (1988) 'Non-Active Role-Playing: Some Experiences'. In A. Eskola, A. Kihlström, D. Kivinen, K. Weckroth and O.-H. Ylijoki (eds.) Blind Alleys in Social Psychology. Advances in Psychology 48. Amsterdam: Elsevier Science Publishers B.V., 239-311.

Fine, G. (1996) 'Justifying Work: Occupational Rhetorics as Resources in Restaurant Kitchens', Administrative Science Quarterly 41(1): 90-115. doi: http://dx.doi.org/10.2307/2393987.

Gergen, K. J. (1999) An Invitation to Social Construction. London: Sage.

Gergen, K. J. and Thatchenkery, T. J. (2004) 'Organization Science as Social Construction: Postmodern Potentials', The Journal of Applied Behavioral Science 40(2): 228-249. doi: http://dx.doi.org/10.1177/0021886396324002.

Grant, D. and Hardy, C. (2004) 'Introduction: Struggles with Organizational Discourse', Organization Studies 25(1): 5-13. doi: http://dx.doi.org/10.1177/0170840604038173.

Halford, S. and Leonard, P. (2006) 'Place, Space and Time: Contextualizing Workplace Subjectivities', Organization Studies 27(5): 657-676. doi: http://dx.doi. org/10.1177/0170840605059453.

Hancock, P. and Tyler, M. (2004) 'MOT Your Life: Critical Management Studies and the Management of Everyday Life', Human Relations 57(5): 619-645. doi: http://dx.doi.org/ 10.1177/0018726704044312.

Harding, N. (2002) 'On the Manager's Body as an Aesthetics of Control', Tamara: Journal of Critical Postmodern Organization Science 2(1): 63-76. Available at http://peaceaware. com/tamara/issues/volume 2/issue 2 1/Harding ManagersBody.pdf.

Harquail, C. V. and King, A. W. (2010) 'Construing Organizational Identity: The Role of Embodied Cognition’, Organization Studies 31(12): 1619-1648. doi: http://dx.doi.org/ 10.1177/0170840610376143.

Hochschild, A. R. (1983) The Managed Heart: Commercialization of Human Feeling. Berkeley: University of California Press.

Hujala, A. and Rissanen, S. (2011) 'Organizational Aesthetics in Nursing Homes', Journal of Nursing Management 19(4): 439-448. doi: http://dx.doi.org/10.1111/j.13652834.2011.01193.x. 
Hujala, A., Rissanen, S. and Vihma, S. (2013) Designing Wellbeing in Elderly Care Homes. Aalto University publication series crossover 2/2013. Finland. [Electronic book] Available: doi: https://aaltodoc.aalto.fi/handle/123456789/11819. Accessed 27.10.2015.

Hvid, H. and Kamp, A. (2012) 'The Future of Elderly Care-Beyond New Public Management?' In A. Kamp \& H. Hvid (eds.) Elderly Care in Transition-Management, Meaning and Identity at Work. A Scandinavian Perspective. Copenhagen: Copenhagen Business School Press, 229-243.

Jacobs, K. and Malpas, J. (2013) 'Material Objects, Identity and the Home: Towards a Relational Housing Research Agenda', Housing, Theory and Society 30(3): 281-292.

Jaros, S. (2012) 'Identity and the Workplace: An Assessment of Contextualist and Discursive Approaches', Tamara-Journal for Critical Organization Inquiry 10(4): 45-59.

Jokinen, A. (1999) 'Vakuuttelevan ja suostuttelevan retoriikan analysoiminen' (Analysis of Persuasive Rhetoric.) In A. Jokinen, K. Juhila \& E. Suoninen (eds.) Diskurssianalyysi liikkeessä (Discourse Analysis in Motion). Tampere: Vastapaino, 126-159.

Kamp, A. (2012) 'Meaning of Work in Elderly Care in Denmark: Fragile Reconstructions'. In A. Kamp \& H. Hvid (eds.) Elderly Care in Transition-Management, Meaning and Identity at Work. A Scandinavian Perspective. Copenhagen Business School Press, 107-132.

Kirpal, S. (2004) 'Work Identities of Nurses. Between Caring and Efficiency Demands', Career Development International 9(3): 274-304. doi: http://dx.doi. org/10.1108/13620430410535850.

Kunda, G. (1992) Engineering Culture. Control and Commitment in a High-Tech Corporation. Philadelphia: Temple University Press.

Kärreman, D. and Alvesson, M. (2004) 'Cages in Tandem: Management Control, Social Identity, and Identification in a Knowledge-Intensive Firm', Organization 11(1): 149-175. doi: http://dx.doi.org/10.1177/1350508404039662.

Leinonen, A. (2009) 'Hoivatyöntekijöiden muutostoiveiden topografia: kannanottoja vanhuksen kohteluun, henkilöstöresursseihin ja ikääntymispolitiikkaan' (Topography of Care Workers' Hopes for Change: Views and Opinions on the Treatment of Older People, Staff Resources and Ageing Policy), Yhteiskuntapolitiikka 74(2): 132-148.

Martin, P. Y. (2002) 'Sensations, Bodies, and the "Spirit of a Place”: Aesthetics in Residential Organizations for the Elderly', Human Relations 55(7): 861-885.doi: http://dx.doi.org/1 $0.1177 / 0018726702055007544$.

Michael, M. (1996) Constructing Identities: the Social, the Nonhuman and Change. London: Sage.

O'Toole, P. and Were, P. (2008) 'Observing Places: Using Space and Material Culture in Qualitative Research', Qualitative Research 8(5): 616-634. doi: http://dx.doi. org/10.1177/1468794108093899.

Potter, J. (1996) Representing Reality. Discourse, Rhetoric and Social Construction. London: Sage.

Pratt, M. G. and Rafaeli, A. (1997) 'Organizational Dress as a Symbol of Multilayered Social Identities', The Academy of Management Journal 40(4): 862-898.

Schraube, E. and Sørensen, E. (2013) 'Exploring Sociomaterial Mediations of Human Subjectivity', Subjectivity 6(1): 1-11. doi: http://dx.doi.org/10.1057/sub.2012.30.

Shotter, J. (1993) Conversational Realities: Constructing Life through Language. London: Sage.

Slay, H. and Smith, D. (2011) 'Professional Identity Construction: Using Narrative to Understand the Negotiation of Professional and Stigmatized Cultural Identities', Human Relations 64(1): 85-107. doi: http://dx.doi.org/10.1177/0018726710384290.

Strati, A. (1992) 'Aesthetic Understanding of Organizational Life', Academy of Management Review 17(3): 568-581. doi: http://dx.doi.org/10.5465/AMR.1992.4282009. 
Strati, A. and Guillet de Montoux, P. (2002) 'Introduction: Organizing Aesthetics', Human Relations 55(7): 755-766. doi: http://dx.doi.org/10.1177/0018726702557001.

Symon, G. (2000) 'Everyday Rhetoric: Argument and Persuasion in Everyday Life', European Journal of Work and Organizational Psychology 9(4): 477-488. doi: http:// dx.doi.org/10.1080/13594320050203094.

Symon, G. (2005) 'Exploring Resistance from a Rhetorical Perspective’, Organization Studies 26(11): 1641-1663. doi: http://dx.doi.org/10.1177/0170840605054626.

Taylor, S. S. and Hansen, H. (2005) 'Finding Form: Looking at the Field of Organizational Aesthetics', Journal of Management Studies 42(6): 1211-1231.

Thomas, R. (2009) 'Critical Management Studies on Identity. Mapping the Terrain'. In M. Alvesson, T. Bridgman \& H. Willmott (eds.) The Oxford Handbook of Critical Management Studies. Oxford: Oxford University Press, 166-185.

Twigg, J. (2000) 'Carework as a Form of Bodywork', Aging and Society 20(4): 389-411.

Twigg, J. (2010) 'Clothing and Dementia: A Neglected Dimension?', Journal of Aging Studies 24: 223-230. doi: http://dx.doi.org/10.1016/j.jaging.2010.05.002.

Ward, J. and McMurray, R. (2016) The Dark Side of Emotional Labour. Abingdon, Oxon: Routledge.

Warren, S. (2008) 'Empirical Challenges in Organizational Aesthetics Research: Towards a Sensual Methodology', Organization Studies 29(4): 559-580. doi: http://dx.doi. org/10.1177/0170840607083104.

Widdicombe, S. (1998) 'Identity as an Analysts' and a Participants' Resource'. In Charles Antaki \& Sue Widdicombe (eds.) Identities in Talk. London: Sage, 191-206.

Widding, I. L. (2002) 'Masculine Dignity and the Dirty Body', NORA-Nordic Journal of Feminist and Gender Research 10(3): 137-146. doi: http://dx.doi.org/10.1080/080387402321012162.

\section{End notes}

${ }^{1}$ We use authentic extracts from the stories in the findings. These extracts are in italics. The letter before the story number refers to stories of good $(G)$ or bad $(B)$ elderly care homes. Extracts from the stories have been translated into English but original linguistic deficiencies have not been corrected.

${ }^{2}$ Capitals in the original.

${ }^{3}$ Capitals in the original.

${ }^{4}$ Capitals in the original. 